\title{
Aging: Basic Concept
}

\author{
Hom Nath Chalise* \\ Population Association of Nepal \\ *Corresponding author: Hom Nath Chalise, Vice President, Population Association of Nepal, Email: chalisehkpp@gmail.com \\ To Cite This Article: Hom Nath Chalise. Aging: Basic Concept. Am J Biomed Sci \& Res. 2019 - 1(1). AJBSR.MS.ID.000503. \\ DOI: 10.34297/AJBSR.2019.01.000503
}

Received 制: December 21, 2018; Published 眥: January 02, 2019

\section{Introduction}

Today, people are living longer than ever before due to advances in education, technology, medicine, food distribution, and sanitary conditions. So, nowadays, it is not unusual to meet people who are in their $70 \mathrm{~s}, 80 \mathrm{~s}, 90 \mathrm{~s}$, and some who are close to 100 years old. However, "adding the years to life," does not mean that we are also able to "add more life to the extra years." In other words, living longer does not always mean we will also have better or a good quality of life in later years. Some older adults in late life are healthy and independent and are still very involved in their family and community lives. Then again, it is not unusual to see older persons who can get very ill and are not able to get themselves out of bed.

Aging is a lifelong process of growing up and growing old. It begins at conception and ends with death. So, in this sense, we are all aging from the time of birth. In our younger years, aging is called by other names. For example, in our infant years, we call aging "growth and development." In our teenage and young adult years, we refer to aging as "maturation." After age 30, our physical body begins to wear out and our functioning declines. This is called "senescence."

Aging includes three parts:

A. Growth and development: In our infant years

B. Maturation: In our teenage and young adult years and

C. Senescence: After age 30. So, aging should be explained based on these three parts.

The human body changes in many noticeable ways with age, and aging is often accompanied by decline in bodily functions. However, a decline in function is different from loss of function that results from disease. Perhaps the first sign of aging occurs when the eye cannot focus easily on close objects. Often by age 40 , many people find it difficult to read without using glasses. Hearing also changes with age. People tend to lose some ability to hear the highest pitched tones. Therefore, older people may find that violin music no longer sounds as exciting as it did when they were younger. Our skin wrinkles and our hair turn gray or white.

The functioning of our internal organs-the heart, lungs, liver, and kidneys-also declines with age. These functions generally peak at about age 30 and then begin a gradual decline. The decline in the functioning of internal organs means that older people are more likely to experience adverse effects from drugs, changes in the environment, toxins, and illness.

All vital organs begin to lose some function as you age during adulthood. Aging changes occur in all of the body's cells, tissues, and organs and these changes affect the functioning of all body systems. Living tissue is made up of cells. There are many different types of cells, but all have the same basic structure. Tissues are layers of similar cells that perform a specific function.

Cells are the basic building blocks of tissues. All cells experience changes with aging. They become larger and are less able to divide and multiply. Among other changes, there is an increase in pigments and fatty substances inside the cell (lipids). Many cells lose their ability to function, or they begin to function abnormally.

Despite this decline, most functions remain adequate throughout life, because most organs have considerably more functional capacity (functional reserve) than the body needs. For example, even if half the liver is destroyed, more than enough liver tissue remains to maintain normal function.

It's important to remember that disease, rather than normal aging, usually accounts for loss of function in old age. Therefore, it is important to be able to distinguish between normal aging and disease, so that diseases can be diagnosed and treated in their early stages.

\section{Different Types of Aging}

Aging can be viewed in different way. We need broader eyes, views to understand the aging related issues. In this context aging 
is classified as biological aging, psychological aging, social aging, chronological aging and functional aging.

\section{Chronological Aging}

Chronological Aging is the number of years a person has lived so far. An 85-year-old lady is chronologically older than a man who is 75 years old. However, chronological age may not match a person's biological, psychological, or social age. For example, the 85-yearold woman may be an active volunteer, while the 75-year-old man could be homebound. Sometimes we say, "he looks younger than his age," or "she does not act her age." In these cases, the biological, psychological, and social age do not match the chronological age.

\section{Biological Aging}

Biological Aging involves the loss of cells over time. With biological aging, tissues and organs are less likely to function efficiently, the body's ability to repair itself slows down, and the immune functions decline, making the body more prone to infection. Biological aging is sometimes referred to as Physical Aging. A person who keeps fit and gets regular check-ups can appear biologically younger than someone who is the same age but does not keep fit.

\section{Psychological Aging}

Psychological Aging involves changes in memory, learning, intelligence, personality, and coping. An older person who is mentally active and is able to deal with new situations can be said to be psychologically young.

\section{Social Aging}

Social Aging refers to changes in roles and relationships as we age. For example, it is not unusual for older people to gain new roles, like becoming grandparents. Or they may change roles, from an employee to a retiree. With role changes in later years, society may expect people to behave in certain ways. So, for some people, it may not be proper for "grandma" to go roller skating or bungee jumping because "these are things that young people do." The social age of a person in a given context can be very important because it shapes the meaning of aging for the person, and this can make aging a positive or negative experience.

\section{Functional aging}

It is related to how people compare psychologically to others to similar age.

\section{Category of older persons}

With increasing life expectancy and number people increasing day by day in the $60+$ category, age 60 years and above is also further classified for the demographic data collection and for other purposes also. In the western and developed countries chronologically 65 years is considered as beginning of aging and accordingly the aging can be classified as:
a) Young old: Year (65 to 74)
b) Middle Old: Year (75 to 84)
c) Old-Old: Years (85+)
d) Centenarians $(100+)$

\section{Changes that Occur with Aging}

As people age, they experience biological, psychological, and social changes. These changes are normal, but there are a lot of things that can be done to help older adults adjust to and compensate for these changes.

\section{Biological Changes}

External Changes: External changes are some of the most obvious changes with aging. These include changes to one's hair, nails, and skin.

\section{a. Changes to the Hair}

As people age, their hair loses its pigment and turns gray or white. As people get older, their hair thins. Many men become bald or have a "receding hairline," but even women notice that their hair becomes less thick. Because the hair disappears or thins, older people are more likely to get sunburned on their heads.

\section{b. Changes to the Nails}

Nails thicken and become rigid and more brittle.

\section{c. Changes to the Skin}

As people get older, skin loses elasticity. It becomes thin and fragile. The blood flow and oil production in the skin decrease, and the skin tends to become dry and wrinkled. "Liver spots" often appear on the hands and face. The skin may look pale and translucent. Sweat glands decrease, and there is an increased risk for heat stroke. Wounds take a longer time to heal in older persons. When these changes happen, older adults are at risk of getting decubitus ulcers (sores that are hard to heal).

\section{Sensory Changes}

Sensory changes include changes to taste, smell, sight, and hearing.

\section{Changes to Taste and Smell}

The senses of taste and smell decline in later years. The danger is that the loss of taste and smell can make it difficult to tell if food is spoiled or if there is a gas leak in the kitchen stove.

The decline in senses of taste and smell can also have serious nutritional outcomes. Tasteless, bland foods can make eating less enjoyable.

\section{Changes in Vision}

As a person gets older, the lens in the eye becomes yellow and thickens. This means that the older eye needs more light than a 
younger eye. The lens of the eye can grow unevenly. This may cause glare problems. A small amount of glare may cause great difficulties for an older adult, and it may cause anxiety or affect their ability to concentrate.

Changes in the lens also make color perception more difficult. It may be hard for older adults to clearly see pastel colors like pale blue, light green, pale yellow, and pale pink. It becomes hard to tell the difference between dark brown, dark blue, and black. Red is the easiest color to see in old age. The older eye does not adjust quickly to changes in levels of light. Sudden changes in lighting may be dangerous and may cause accidents and falls. Conditions of the eye can cause vision loss. More than half of severe visual impairment occurs in people 65 and older. However, this does not always make older people totally blind. Many people can still function with moderate vision loss.

\section{Changes in Hearing}

There is a decline in the hearing ability of older persons. Hearing loss is worse at high frequencies. So, high pitched sounds may be more difficult to hear than low-pitched sounds. Changes in hearing may mean that
a. Some sounds will be heard and others may not,
b. Some sounds may be distorted or heard incorrectly,
c. Things are heard incorrectly and misinterpreted.

Many people don't want to admit that they can't hear and might "cover up" by just smiling or nodding at whatever you say.

Organ System Changes: These include changes to the heart and cardiovascular system, the lungs and respiratory system, the gastrointestinal system, the urinary tract system, and the musculoskeletal system.

\section{Changes to the Heart and Cardiovascular System}

With age, the heart pumps with less force, and there is a decrease in cardiac output. More time is required for the heart to return to normal after exertion.

\section{Changes to the Lungs and Respiratory System}

Deep breathing may become difficult because the skeletal muscles become more rigid. The cough mechanism becomes less effective due to anatomic and muscle changes. Breathing moves to the upper part of the chest. The lungs become less elastic and decrease in size.

\section{Changes to the Musculoskeletal System}

We reach our maximum height at age 25. After that, height declines an average of 3 inches over the life span, due to loss of bone. With age, the width of the shoulders declines. There is bone loss, weakened muscles, and loss of elasticity in ligaments. Cartilage between joints wears thin, and lubricating fluid decreases, causing stiffness in the joints. Joint stiffness limits physical activity and mobility. This affects gait and posture. With declines in physical activity, strength and stamina will also be affected.

\section{Changes to the Gastrointestinal System}

With age, there is a decrease in the contraction of muscles in the esophagus, so it takes more time for food to get to the stomach. This explains why many older adults have the sensation of being full before finishing a full meal. This can result in inadequate nutrient intake.

\section{Changes to the Urinary Tract}

With age, kidneys decrease in size and volume, this affects renal function. This makes the need to urinate more frequent. The bladder may not empty completely after voiding. This can lead to urinary tract infections. Weak muscles of the bladder can lead to incontinence (the inability to control bladder functions).

\section{Psychological Changes}

In normal aging, people become slower at "recalling" facts. It takes them a longer time to "react" to things. However, if given enough time, they may be very functional. Learning can be a challenge if elders have problems with their hearing or eyesight. Learning and memory can be impaired if the environment is noisy, uncomfortable, or unpleasant. Learning and memory can be impaired due to illness, overmedication, depression, and stress.

\section{Social Changes}

Elders experience many losses. Their children grow up and leave home, they retire from work, they experience physical declines, and their older friends start to die. Most elders live on fixed incomes. When elders can't live on their own, they have to live with others, for example with family or friends or in nursing homes. When elders are lonely and frail, they can become victims of fraud and abuse. 